\title{
Amyloid-like Fibrils from an $\alpha$-Helical Transmembrane Protein
}

\author{
Karen Stroobants, ${ }^{\dagger}$ Janet R. Kumita, ${ }^{\dagger}$ Nicola J. Harris, ${ }^{\ddagger}$ Dimitri Y. Chirgadze, ${ }^{\S}$ Christopher M. Dobson, \\ Paula J. Booth, ${ }^{*}$ and Michele Vendruscolo*,
}

${ }^{\dagger}$ Department of Chemistry, University of Cambridge, Cambridge CB2 1EW, U.K.

"Department of Chemistry, King's College London, London SE1 1DB, U.K.

${ }^{\S}$ Department of Biochemistry, University of Cambridge, Cambridge CB2 1GA, U.K.

\section{Supporting Information}

ABSTRACT: The propensity to misfold and self-assemble into stable aggregates is increasingly being recognized as a common feature of protein molecules. Our understanding of this phenomenon and of its links with human disease has improved substantially over the past two decades. Studies thus far, however, have been almost exclusively focused on cytosolic proteins, resulting in a lack of detailed information about the misfolding and aggregation of membrane proteins. As a consequence, although such proteins make up approximately $30 \%$ of the human proteome and have high propensities to aggregate, relatively little is known

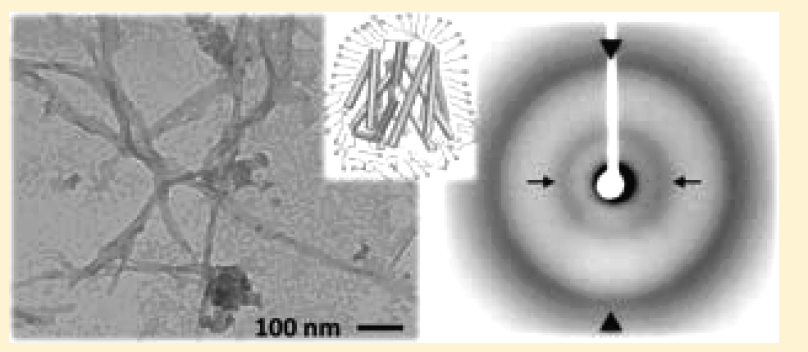
about the biophysical nature of their assemblies. To shed light on this issue, we have studied as a model system an archetypical representative of the ubiquitous major facilitator superfamily, the Escherichia coli lactose permease (LacY). By using a combination of established indicators of cross- $\beta$ structure and morphology, including the amyloid diagnostic dye thioflavin-T, circular dichroism spectroscopy, Fourier transform infrared spectroscopy, X-ray fiber diffraction, and transmission electron microscopy, we show that LacY can form amyloid-like fibrils under destabilizing conditions. These results indicate that transmembrane $\alpha$-helical proteins, similarly to cytosolic proteins, have the ability to adopt this generic state.

\begin{abstract}
A wide range of medical conditions, including neurodegenerative disorders such as Alzheimer's and Parkinson's diseases, are associated with the misfolding and aggregation of specific proteins into amyloid fibrils. ${ }^{1-4}$ In vivo and in vitro studies of these disease-related aggregates have led to the recognition of their common structural features, despite the diversity of the amino acid sequences and native state structures of the proteins by which they are formed. ${ }^{4}$ In particular, it has been shown that amyloid fibrils possess a cross- $\beta$ architecture, in which the $\beta$-strands that make up the $\beta$ sheets are perpendicular to the fibril axis. ${ }^{2,4,5}$ As this fibrillar architecture can be adopted by a wide variety of different proteins, $^{6-9}$ it has been suggested that polypeptide chains have a generic ability to form amyloid fibrils.

Despite a growing body of evidence of the widespread nature of the amyloid phenomenon, ${ }^{3,4,6}$ little evidence has been obtained about this type of behavior in the case of membrane proteins. This absence of information is particularly remarkable, as it is well-known that the highly hydrophobic nature of membrane proteins makes them prone to self-association and aggregation under many conditions. ${ }^{11}$ Indeed, hundreds of membrane proteins have been observed to aggregate upon aging in Caenorhabditis elegans, ${ }^{12}$ and a set of genes found to be associated with human neurodegenerative disorders has been linked with membrane proteins involved in the oxidative phosphorylation pathway. ${ }^{13}$ In addition, predictive models of protein homeostasis indicate that the aggregation propensity of
\end{abstract}

membrane proteins is very high. ${ }^{14}$ Moreover, the amyloid- $\beta$ peptide $(\mathrm{A} \beta)$, which is associated with Alzheimer's disease, is a proteolytic fragment of the membrane protein APP, ${ }^{15}$ and the aggregation and formation of fibrils by fragments of luminal membrane protein domains have been reported. ${ }^{16}$

Several reasons lie behind the current lack of detailed structural information about membrane protein aggregation, many of which are related to the challenges inherent in their recombinant production and purification. These steps remain among the major bottlenecks in many structural and functional analyses of these important biological components. ${ }^{17}$ In contrast to the situation for cytosolic proteins, membrane proteins often require expression and purification procedures to be performed in lipid or detergent environments. ${ }^{18}$ Despite these difficulties, a more detailed knowledge of this group of proteins is absolutely essential for the understanding of normal and aberrant biological processes, as they represent $\sim 30 \%$ of the human proteome $\mathrm{e}^{19}$ and comprise a substantial fraction of currently known drug targets. $^{20}$

Moreover, an increased level of $\beta$-sheet structure has sparsely been reported for disease-related membrane proteins. Perhaps the best studied of these proteins is cystic fibrosis transmembrane conductance regulator (CFTR), an ABC transporter

Received: February 20, 2017

Revised: $\quad$ May 9, 2017

Published: May 11, 2017 
containing 12 transmembrane helices. Several mutations of this membrane protein result in a variety of cystic fibrosis phenotypes, $^{21}$ spanning defects in synthesis, processing, trafficking, and functional deficits. Although most studies report a fast degradation of dysfunctional CFTR rather than formation of deposits, ${ }^{22}$ it has been indicated that misfolded aggregates with highly organized arrays of $\beta$-strands can form for the P205 variant. ${ }^{23}$ Retinitis pigmentosa, a progressive retinal degenerative disease, has been shown to be associated with mutations in rhodopsin, an $\alpha$-helical membrane protein of the G-coupled protein receptor (GCPR) family. ${ }^{24}$ Indeed, because a majority of these mutations result in the incorrect folding of the apoprotein opsin, retinitis pigmentosa has been classified as a protein misfolding disease. ${ }^{25,26}$ Despite the fact that misfolded opsin was initially presumed to form disordered aggregates in the endoplasmic reticulum (ER), ${ }^{27}$ it has recently been shown that aggregates of the opsin variants G188R and $\mathrm{P} 23 \mathrm{H}$, formed in HEK293 cells, exhibit a high $\beta$-structure content. ${ }^{28}$ These aggregates appear to be distinct from amyloid fibrils because they do not enhance the fluorescence of thioflavin-T (ThT). ${ }^{28}$ A stronger tendency to form ordered $\beta$-sheet structure has also been reported for a model peptide with the partial sequence of a transmembrane domain of peripheral myelin protein 22 (PMP22). ${ }^{29}$ PMP22 is an $\alpha$-helical transmembrane glycoprotein primarily expressed in Schwann cells, and its mutations are known to cause the peripheral neuropathy Charcot-Marie-Tooth disease. ${ }^{30}$ Aggresome formation by this protein has been reported upon its overexpression in mice, although the structure of the protein within these aggregate-rich inclusions is not yet clear. ${ }^{31}$ In addition, there is recent evidence of the formation of ThT-positive aggregates of the $\beta$-barrel transmembrane domain of outer membrane protein A (OmpA) formed in the absence of lipid or lipid-mimetic membranes and in the presence of high concentrations of urea. ${ }^{32}$

Overall, although increases in the level of $\beta$-sheet structure have been reported in a number of cases, ${ }^{23,28,31,32}$ it remains unclear whether membrane proteins have an inherent propensity to convert into amyloid fibrils similar to that of cytosolic proteins. To address this problem, we have studied LacY, a representative of the major facilitator superfamily of transporters that are prevalent across prokaryotes and eukaryotes. This 417-residue protein is composed of 12 transmembrane $\alpha$-helices arranged in two domains, with a substrate binding site at the domain interface. ${ }^{33}$ Its crystal structure has been determined to $3.6 \AA$ resolution, ${ }^{34}$ and its function has been studied in great detail. ${ }^{35}$ The structure and in vitro folding of LacY have been studied within both micelles and liposomes. ${ }^{36-38}$ These simple lipid-mimetic systems represent an ideal starting point for biophysical studies, and the relevance of their use is supported by extensive studies showing the tolerance of membrane proteins to changing lipid environments. ${ }^{39}$

We should mention that, in vivo, LacY is translated directly into lipid membranes in Escherichia coli, in the same way that most membrane proteins are directly translated into the ER membrane where they then reside. ${ }^{40}$ Furthermore, a network of quality-control mechanisms has co-evolved with the biosynthesis and trafficking of membrane proteins in the ER, with the specific purpose of preventing their aggregation. ${ }^{41}$ By contrast, in our in vitro study, we observe aggregation reactions in a convenient detergent system. Although these conditions are nonphysiological, and our in vitro assays also lack the protein homeostasis controls present in the cellular environment, they allow us to explore the range of structural states accessible to LacY. Consistently, a number of experimental studies have already provided evidence of membrane protein aggregation within the cellular environment. For example, even if in many proteomics protocols membrane proteins tend to be discarded prior to analysis, ${ }^{42}$ several studies have reported the presence of membrane proteins in aggregates found in disease tissues. In particular, lysosomal ATPase and mitochondrial ATPase components have been found to co-aggregate in post-mortem amyloid plaques ${ }^{43}$ and neurofibrillary tangles, ${ }^{44}$ respectively, and the accumulation of the Parkin-associated transmembrane receptor Pael-R in Lewy bodies has been reported. ${ }^{45}$ These examples indicate that membrane proteins under stress can aggregate in vivo outside their native environments.

We report here the conversion of $\mathrm{LacY}$ into fibrillar aggregates with the characteristic features of cross $-\beta$ structure and therefore demonstrate that an $\alpha$-helical membrane protein can adopt a stable amyloid-like state analogous to those observed for cytosolic proteins.

\section{MATERIALS AND METHODS}

Generation of the Aggregation Propensity Profile of LacY. The CamSol method ${ }^{46}$ was used to calculate the sequence-dependent intrinsic solubility of LacY, which we adopted as an indicator of its aggregation propensity, as both solubility and aggregation propensity describe the tendency of proteins to convert from the native state to insoluble aggregates. The CamSol method was derived by considering the physicochemical properties of the amino acid sequences that are most responsible for their aggregation behavior, including in particular the hydrophobic patterns, which tend to drive the aggregation process, and the presence of "gatekeeper" residues (charged residues and prolines), which tend to prevent it. ${ }^{46}$ The indication of $\alpha$-helices and coil in the figure was based on the native structure of LacY.34,47

LacY Expression and Purification. LacY was purified as previously described ${ }^{37}$ with modifications. LacY was expressed in One Shot BL21-AI chemically competent E. coli (Thermo Fisher Scientific, Paisley, U.K.), using the kanamycin resistant plasmid pET-28a. The cultures were grown at $37{ }^{\circ} \mathrm{C}$ in $\mathrm{LB}$ medium and induced with $0.1 \%$ arabinose and $1 \mathrm{mM}$ isopropyl $\beta$-D-1-thiogalactopyranoside at an $\mathrm{OD}_{600}$ of $0.7-0.8 \mathrm{AU}$, and the cells were harvested by centrifugation ( $5000 \mathrm{~g}$ for $45 \mathrm{~min}$ ). Following growth and induction, the cells were lysed by three cycles in a high-pressure homogenizer, and the membranes were sedimented by centrifugation $\left(100000 \mathrm{~g}\right.$ for $4{ }^{\circ} \mathrm{C}$ at 30 min) (ultracentrifuge, rotor $70 \mathrm{Ti}$, Beckman Coulter, High Wycombe, U.K.). The pellets were resuspended and incubated $\left(4{ }^{\circ} \mathrm{C}\right.$ for $\left.2 \mathrm{~h}\right)$ in $25 \mathrm{~mL}$ of solubilization buffer $[200 \mathrm{mM} \mathrm{NaCl}$, $20 \mathrm{mM}$ imidazole, $10 \mathrm{mM} \beta$-mercaptoethanol, $40 \mathrm{mM}$ DDM, and an EDTA free protease inhibitor cocktail tablet (Roche Diagnostics Ltd., Burgess Hill, U.K.)]. The solubilized membranes were centrifuged $\left(100000 \mathrm{~g}\right.$ and $4{ }^{\circ} \mathrm{C}$ for $\left.30 \mathrm{~min}\right)$, and the supernatant was retained for purification. For all steps of purification, the buffer contained $50 \mathrm{mM}$ sodium phosphate ( $\mathrm{pH} 7.4), 10 \%(\mathrm{v} / \mathrm{v})$ glycerol, $10 \mathrm{mM} \beta$-mercaptoethanol, and $1 \mathrm{mM}$ DDM, with additional components indicated in brackets. Initial purification was performed with a $1 \mathrm{~mL}$ HisTrap HP $\mathrm{Ni}^{2+}$ affinity column (GE Healthcare Ltd., Little Chalfont, U.K.), previously equilibrated with 10 column volumes (CV) of purification buffer ( $20 \mathrm{mM}$ imidazole). Following loading of the sample, the column was washed with $50 \mathrm{CV}$ of purification 

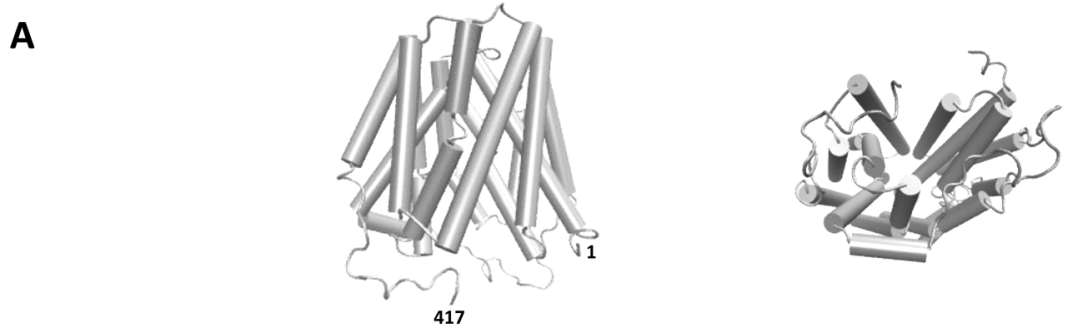

B

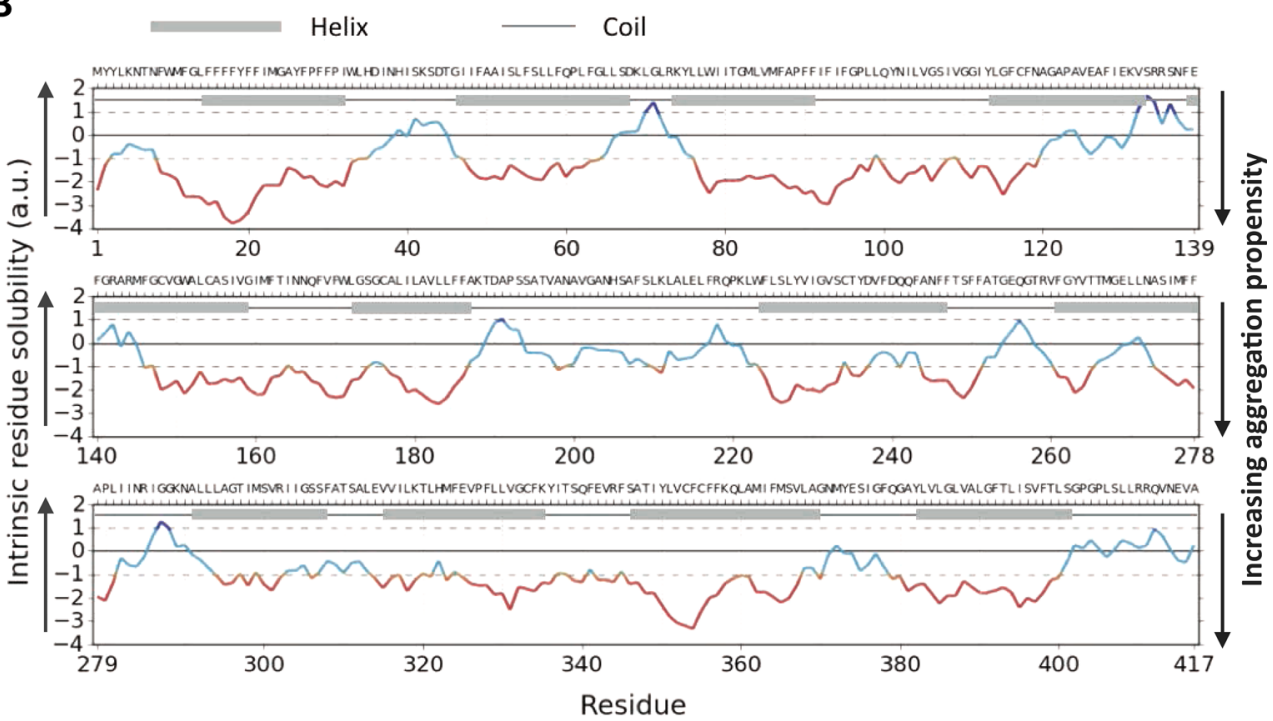

Figure 1. CamSol profile of LacY, as an indicator of its aggregation propensity. (A) Native structure of LacY (front and bottom view), which is shown for reference. The Protein Data Bank structure $2 \mathrm{~V}^{3} \mathrm{~N}^{34}$ was used to draw the cartoons, with cylinders representing $\alpha$-helices and ribbons representing disordered coils. (B) $\mathrm{CamSol}^{46}$ profile of LacY (see Materials and Methods). Regions colored red have a low intrinsic solubility and hence a high aggregation propensity. The positions of $\alpha$-helices (as derived from ref 47) are indicated by horizontal gray bars.

buffer (20 mM imidazole) and LacY was eluted with $5 \mathrm{CV}$ of elution buffer ( $75 \mathrm{mM}$ imidazole). The eluted protein was transferred directly to a gel filtration column (SUP200 Superdex, GE Healthcare) to remove imidazole as well as multimeric protein species. The resulting protein fractions were analyzed by sodium dodecyl sulfate-polyacrylamide gel electrophoresis (SDS-PAGE) using NuPAGE 4 to $12 \%$ gels with MES buffer (Thermo Fisher Scientific) and UV-vis spectroscopy to verify the purity of the protein samples and determine their concentrations, respectively. The LacY concentration in the supernatant was determined from the absorbance at $280 \mathrm{~nm}$, using an $\varepsilon_{\mathrm{LacY}}$ of $76391 \mathrm{M}^{-1} \mathrm{~cm}^{-1}$. After purification, aliquoted samples were frozen in liquid $\mathrm{N}_{2}$ and stored at $-80{ }^{\circ} \mathrm{C}$ until they were used.

LacY Aggregation Procedure. LacY in $50 \mathrm{mM}$ sodium phosphate and $0.05 \% \operatorname{DDM}(\mathrm{pH} 7.4)$ was used directly as obtained from the purification $(2 \mu \mathrm{M}, 4 \mu \mathrm{M}$, and occasionally 8 $\mu \mathrm{M}$ samples) or concentrated (to 8,16 , or $32 \mu \mathrm{M}$ ), and aggregation was initiated by increasing the temperature of the sample to $37{ }^{\circ} \mathrm{C}$. When concentration of the protein was required, Vivaspin 20 concentrators with a $100 \mathrm{kDa}$ cutoff (Millipore, Watford, U.K.) were used as these devices were reported to cause insignificant changes in the DDM concentration. $^{48,49}$ The final DDM concentration was determined via colorimetric determination of the glycoside content. ${ }^{49}$ The samples were continuously kept on ice or at 4 ${ }^{\circ} \mathrm{C}$ to minimize aggregate formation prior to any measurement. Concentrating the samples took approximately $35 \mathrm{~min}$ from defrosting. Samples were used immediately after being concentrated and were not refrozen.

ThT Fluorescence Assay. LacY (2, 4, and $8 \mu \mathrm{M}$ as obtained after purification) in $50 \mathrm{mM}$ sodium phosphate and $0.05 \% \mathrm{DDM}(\mathrm{pH} 7.4)$ was incubated at $37^{\circ} \mathrm{C}$ in the presence of $4 \mu \mathrm{M}$ ultrapure ThT (Sigma-Aldrich, Dorset, U.K.). The change in the ThT fluorescence intensity (excitation at $440 \mathrm{~nm}$, emission at $480 \mathrm{~nm}$ ) was monitored over $48 \mathrm{~h}$ using a FLUOstar Optima plate reader (BMG Labtech, Aylesbury, U.K.) under quiescent conditions. Corning 96-well plates with half-area (black/clear bottom polystyrene) nonbinding surfaces (Fisher Scientific, Loughborough, U.K.) were used.

Analysis of LacY in the Supernatant. At the end of an aggregation experiment, the samples were centrifuged $(15000 \mathrm{~g}$ for $15 \mathrm{~min})$, and the concentration of the free monomer was calculated by measuring the UV-vis spectrum of the supernatant. The same samples were analyzed via SDSPAGE. An aliquot of the LacY supernatant solution $(15 \mu \mathrm{L})$ was mixed with NuPAGE LDS sample buffer (ThermoFisher Scientific), and $10 \mu \mathrm{L}$ of the solution was run on a NuPAGE 4 to $12 \%$ Bis-Tris gel (ThermoFisher Scientific). A tricolor protein marker (Stratech Scientific, Suffolk, U.K.) was run on the same gel. The gel was stained with InstantBlue (Expedeon, Swavesey, U.K.).

Circular Dichroism Spectroscopy. A LacY solution (2 $\mu \mathrm{M})$ in $50 \mathrm{mM}$ phosphate buffer and $0.05 \% \mathrm{DDM}(\mathrm{pH} 7.4)$, before and after incubation at $37^{\circ} \mathrm{C}$ for $48 \mathrm{~h}$, was deposited in a circular cell. Far-UV CD spectra were recorded on a model 410 Aviv circular dichroism spectrophotometer (Biomedical 
Inc., Lakewood, NJ), with specially adapted sample detection (the detector is placed closer to the sample) to minimize scattering artifacts. Quartz circular cells were used, and CD spectra were obtained by averaging two to five individual spectra recorded between 260 and $190 \mathrm{~nm}$ at a $0.5 \mathrm{~nm}$ interval with an averaging time of $2 \mathrm{~s}$. For each protein sample, the CD signal of the buffer without protein was recorded and subtracted from the $\mathrm{CD}$ signal of each protein sample. The multiple scans were averaged, and the buffer background was subtracted. The data were then converted from millidegrees to mean residue ellipticity. ${ }^{50}$

Fourier Transform Infrared Spectroscopy. A LacY solution (concentrated to $16 \mu \mathrm{M}$ ) in $50 \mathrm{mM}$ phosphate buffer and $0.05 \% \mathrm{DDM}$ ( $\mathrm{pH} 7.4$ ), before and after incubation at 37 ${ }^{\circ} \mathrm{C}$ for $48 \mathrm{~h}$, was deposited $(10 \mu \mathrm{L})$ into a BioATR cell (Bruker Optics, Coventry, U.K.). Fourier transform infrared (FT-IR) absorption spectra were collected in absorbance mode on an FT-IR Vertex 70 (Bruker) spectrometer fitted with a BioATR cell (Bruker Optics, Coventry, U.K.). Spectra were corrected for the presence of $50 \mathrm{mM}$ sodium phosphate $(\mathrm{pH}$ 7.4) and $0.05 \%$ DDM. The secondary derivative for each spectrum was calculated using OriginPRO. To reduce the noise, a FFT filter (10 pt) was initially applied; the curves were successively normalized and smoothed by a Savitski-Golay filter ( 9 points).

Transmission Electron Microscopy. LacY solutions (concentrated to $16 \mu \mathrm{M}$ ) in $50 \mathrm{mM}$ phosphate buffer and $0.05 \% \mathrm{DDM}$ ( $\mathrm{pH} 7.4$ ) were incubated at $37^{\circ} \mathrm{C}$ for $48 \mathrm{~h}$, and 5 $\mu \mathrm{L}$ of the sample was applied to carbon-coated 400 mesh copper grids (EM Resolutions, Saffron Walden, U.K.). Samples were stained with $2 \%(\mathrm{w} / \mathrm{v})$ uranyl acetate and imaged using a FEI Tecnai $\mathrm{G}_{2}$ transmission electron microscope (Cambridge Advanced Imaging Centre (CAIC), University of Cambridge). Images were analyzed using the SIS Megaview II Image Capture system (Olympus).

X-ray Fiber Diffraction Pattern Analysis. LacY solutions (concentrated to 16 and $32 \mu \mathrm{M}$ ) in $50 \mathrm{mM}$ phosphate buffer and $0.05 \%$ DDM (pH 7.4) were incubated at $37{ }^{\circ} \mathrm{C}$ for $48 \mathrm{~h}$. The samples for fiber diffraction were dialyzed against $50 \mathrm{mM}$ sodium phosphate ( $\mathrm{pH} 7.4$ ) and $0.05 \% \mathrm{DDM}$, and a $5 \mu \mathrm{L}$ aliquot was pipetted between wax stalks and left to dry. The experiments were performed at the Crystallographic X-ray Facility of the Department of Biochemistry of the University of Cambridge. X-rays with a wavelength of $1.5418 \AA$ were produced by a rotating copper anode MISCROSTAR generator (Bruker-AXS, Ltd.), collimated, and focused by HELIOS-MX high-brightness multilayer X-ray optics. Images were acquired on a PLATINUM135 CCD area detector (Bruker-AXS, Ltd., Rigaku-MSC). The exposure time for the diffraction images was $60 \mathrm{~s}$ in each case. Viewing and analysis of the diffraction pattern were performed using the PORTEUM2 software package (PROTEUM 2 User Manual, Bruker AXS, 2010).

\section{RESULTS AND DISCUSSION}

LacY Has a Strong Intrinsic Propensity to Aggregate. In a preliminary assessment, we used the CamSol method ${ }^{46}$ to calculate the sequence-dependent solubility of LacY (Figure 1), which is inversely related to the aggregation propensity score (see Materials and Methods). As the native state of LacY comprises 12 transmembrane $\alpha$-helices, the sequence may be expected to include highly hydrophobic and aggregation-prone regions outside its natural lipid environment, which are indeed present (red regions in the sequence profile in Figure 1).
LacY Readily Forms Aggregates at $37^{\circ} \mathrm{C}$ and pH 7.4. LacY was expressed and purified into $n$-dodecyl $\beta$-D-maltoside (DDM) micelles according to standard procedures. ${ }^{37}$ The detergent was used at a concentration of $1 \mathrm{mM}$ (or $0.05 \%$ ) in all experiments, which is well above its critical micelle concentration (CMC) of $0.16 \mathrm{mM}^{51}$ Long chain maltoside detergents are generally used for LacY purification as they are well-known to effectively maintain the protein in solution. ${ }^{52}$ In addition, it was established that LacY is stabilized by low temperature and glycerol, ${ }^{52}$ which was added in all purification buffers (Materials and Methods). Despite these considerations, purification of $\mathrm{LacY}$ is challenging as the protein tends to aggregate readily at room temperature and even when kept on ice for a few hours. Furthermore, as several biophysical techniques utilized in our studies require protein concentrations (in the range of at least $15-30 \mu \mathrm{M}$ ) higher than those initially obtained from the purification (typically in the range of $2-6 \mu \mathrm{M})$, the samples often required concentrating, thereby placing the protein under conditions where it is particularly vulnerable to aggregation prior to the start of any experiment. This aspect of the system made it difficult to characterize the precise starting point of the aggregation reaction and to avoid consistently the presence of a small fraction of aggregated species at the initiation of the experiments.

In the experimental protocol described here, LacY [in 50 $\mathrm{mM}$ sodium phosphate ( $\mathrm{pH} 7.4)$ and $0.05 \% \mathrm{DDM}]$ was used as obtained from the purification procedure $(2,4$, and $8 \mu \mathrm{M}$ samples) or concentrated to 8,16 , or $32 \mu \mathrm{M}$. Amyloid-like structures often are observed under conditions that destabilize the protein under study, ${ }^{7}$ and as an increase in temperature in particular is known to destabilize LacY, ${ }^{52}$ aggregation of the protein was initiated by increasing the temperature of the sample from 4 to $37^{\circ} \mathrm{C}$. Visible precipitation of $\mathrm{LacY}$ in the micellar environment was observed after approximately $4 \mathrm{~h}$ for the $16 \mu \mathrm{M}$ samples to approximately $8 \mathrm{~h}$ for the $2 \mu \mathrm{M}$ samples, with increasing turbidity of the solutions at longer incubation times of $\leq 48 \mathrm{~h}$. Aliquots taken at different time points during the incubation were centrifuged, and the supernatant at each time point was analyzed. The concentration of $\mathrm{LacY}$ in the supernatant at each time point was obtained from UV-vis spectra at $280 \mathrm{~nm}$ (Table 1) and observed to decrease gradually over time, resulting in $<20 \%$ of the initial protein remaining in solution after incubation for $48 \mathrm{~h}$. This ratio is consistent for the samples at higher concentrations. The same samples were

Table 1. LacY Concentrations in the Supernatant over Time $^{a}$

\begin{tabular}{|ccc} 
time $(\mathrm{h})$ & $A_{280}$ & $c(\mu \mathrm{M})$ \\
0 & 0.148 & 1.94 \\
2 & 0.128 & 1.68 \\
4 & 0.089 & 1.15 \\
6 & 0.085 & 1.11 \\
24 & 0.052 & 0.68 \\
48 & 0.031 & 0.40
\end{tabular}

${ }^{a}$ LacY solutions $(2 \mu \mathrm{M})$ incubated in $50 \mathrm{mM}$ phosphate buffer $(\mathrm{pH}$ 7.4 ) with $0.05 \% \mathrm{DDM}\left(37^{\circ} \mathrm{C}\right.$ for $48 \mathrm{~h}$ ) were centrifuged after $0,2,4$, 6,24 , and $48 \mathrm{~h}$ to precipitate the aggregated fraction, and the UV-vis signal at $280 \mathrm{~nm}$ of the remaining supernatant was monitored. The $\mathrm{LacY}$ concentration in the supernatant was determined from the absorbance at $280 \mathrm{~nm}$, using an $\varepsilon_{\mathrm{LacY}}$ of $76391 \mathrm{M}^{-1} \mathrm{~cm}^{-1}$. An average of two measurements from separate samples is shown (standard deviation \pm 0.005 for $A_{280}$ ). 
analyzed by SDS-PAGE (Figure 2), and the increasingly faint bands observed for the samples after increasing incubation

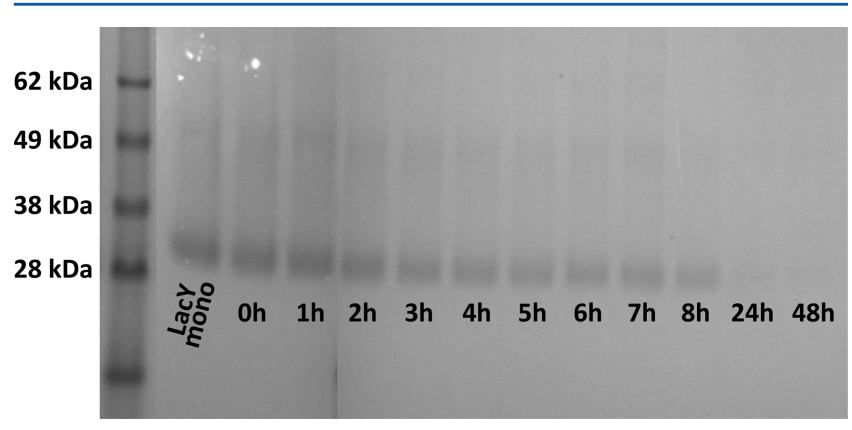

Figure 2. Fraction of $\mathrm{LacY}$ in the supernatant over time. LacY solutions $(2 \mu \mathrm{M})$ incubated in $50 \mathrm{mM}$ phosphate buffer $(\mathrm{pH} 7.4)$ with $0.05 \% \mathrm{DDM}\left(37{ }^{\circ} \mathrm{C}\right.$ for $\left.48 \mathrm{~h}\right)$ were centrifuged to precipitate the aggregated fraction, and the remaining supernatant was analyzed by SDS-PAGE after $0,1,2,3,4,5,6,7,8,24$, and $48 \mathrm{~h}$ (as indicated). LacY appears at $\sim 28 \mathrm{kDa}$ because it does not unfold in SDS and thus runs in its folded state (its expected MW is $48 \mathrm{kDa}$ ). The experiment was repeated twice; a representative data set is shown.

times confirm the nearly complete conversion of the monomer into precipitating species after $48 \mathrm{~h}$.

In the following sections, we describe a range of biophysical techniques that we have used to define the structural nature of the observed aggregates and to characterize their properties. Because nearly complete precipitation of LacY from solution was observed after $48 \mathrm{~h}$, we did not extend experiments beyond this initial time frame.

LacY Aggregates Are ThT-Positive. Amyloid-specific fluorescent dyes have been used for many years to identify amyloid assemblies, ${ }^{1}$ and in vitro assays involving these compounds remain a powerful approach to characterizing amyloid-like fibrils and to monitoring the kinetics of their formation. One of the most widely used dyes is ThT, a positively charged benzothiazole salt that shows increased fluorescence upon interaction with amyloid fibrils. ${ }^{53}$ Membrane proteins are highly hydrophobic in nature and could therefore adopt a mode of binding to ThT different from that of cytosolic proteins. Although some studies have suggested that binding of ThT to amyloid fibrils involves the formation of ThT micelles as a result of hydrophobic interactions, ${ }^{54}$ a model in which ThT specifically interacts with the cross- $\beta$ strands that characterize the unique amyloid architecture is more widely accepted. ${ }^{53}$

LacY solutions at concentrations of 2,4 , and $8 \mu \mathrm{M}$ were incubated at $37{ }^{\circ} \mathrm{C}$ in the presence of $4 \mu \mathrm{M}$ ThT, and the fluorescence signal was monitored over the course of $48 \mathrm{~h}$. Within minutes, an increase in the fluorescence intensity at 480 $\mathrm{nm}$ was observed, and sigmoidal aggregation curves were obtained by plotting the relative fluorescence intensities as a function of time (Figure 3). The initial high intensities, which were seen in all samples, are often observed in this type of kinetic experiment and can be attributed to an equilibration at the higher temperature (from 4 to $37{ }^{\circ} \mathrm{C}$ in this case). Normalization of the data shows an increase in the aggregation rate with an increasing initial protein concentration $(\leq 8 \mu \mathrm{M}$, as these samples could be obtained directly after purification without the need for concentration) (Figure 3B). The ThTpositive character of the $\mathrm{LaCY}$ aggregates provides a first indication that they may have a $\beta$-sheet-rich amyloid-like nature. The enhanced fluorescence of ThT inside micelles, however, could be a result of electrostatic interactions with the charged detergent molecules. ${ }^{55}$ Indeed, significant effects of this type have been observed for ThT simply in the presence of the anionic surfactant sodium dodecyl sulfate (SDS), whereas relatively insignificant intensity changes were observed with neutral detergents such as Tween 20 and Triton X-100. ${ }^{55}$ Because DDM belongs to the latter category of detergents, only minor intensity changes were expected, and none were observed, in its presence (Figure S1). All spectra were corrected for potential buffer effects by monitoring the ThT fluorescence in sodium phosphate buffer containing DDM concentrations equal to those of the sample under investigation, showing that the increase in ThT fluorescence correlates with the presence of LacY aggregates as determined by centrifugation.

LacY Is Converted from $\boldsymbol{\alpha}$-Helical to Parallel $\boldsymbol{\beta}$-Sheet Structure. In addition to monitoring dye binding properties, direct detection of their characteristic $\beta$-sheet architecture is a key parameter in the identification of amyloid-like fibrils. Circular dichroism (CD) and FT-IR spectroscopies are powerful techniques used to characterize protein secondary structure content and were used to monitor the changes in the LacY secondary structure upon aggregation. ${ }^{56}$ The native LacY monomer has been studied extensively; an $\alpha$-helical structure
A

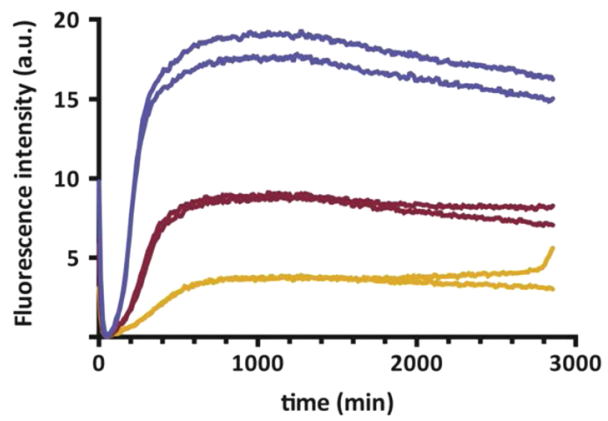

B

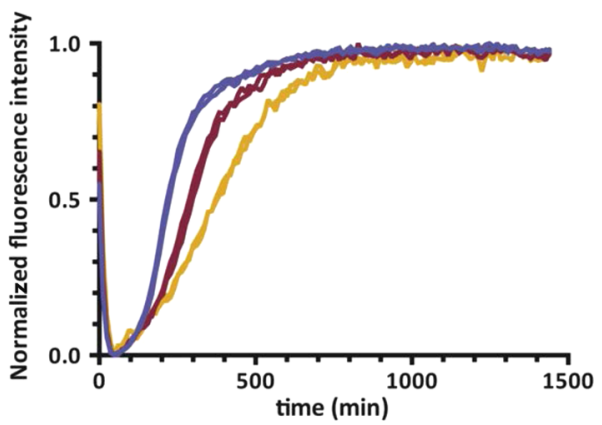

Figure 3. Enhancement of ThT fluorescence by LacY aggregates. (A) ThT fluorescence changes in monomer solutions of $2 \mu \mathrm{M}$ (yellow), $4 \mu \mathrm{M}$ (red), and $8 \mu \mathrm{M}$ (blue) LacY (in duplicate) in $50 \mathrm{mM}$ sodium phosphate ( $\mathrm{pH} \mathrm{7.4)}$ with $0.05 \%$ DDM. The solutions were incubated ( $37{ }^{\circ} \mathrm{C}$ for $48 \mathrm{~h}$ ) in the presence of $4 \mu \mathrm{M}$ ThT, and the ThT fluorescence was continuously monitored. The fluorescence spectra were corrected for the signal in 50 $\mathrm{mM}$ sodium phosphate ( $\mathrm{pH} 7.4$ ) with $0.05 \%$ DDM. (B) The spectra shown in panel A were normalized by subtracting the minimum and dividing by the maximal fluorescence intensity for the respective data set. This procedure allows a straightforward comparison of the slopes of the intensity profiles for different concentrations. The experiment was repeated five times; a representative data set is presented. 
content of $\sim 85 \%$ has been reported from CD measurements and is consistent with the crystal structure. ${ }^{57}$

Aliquots from a LacY solution at a concentration of $2 \mu \mathrm{M}$ were taken before and after incubation at $37{ }^{\circ} \mathrm{C}$ for $48 \mathrm{~h}$, and $\mathrm{CD}$ spectra were recorded for each sample (Figure 4 ). The

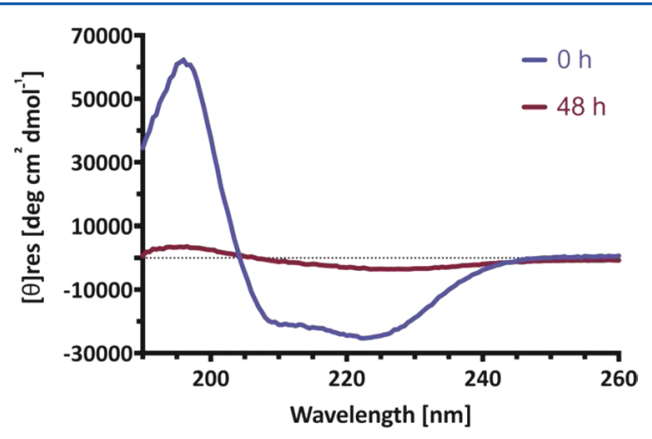

Figure 4. CD intensity decrease upon aggregation of LacY. LacY (2 $\mu \mathrm{M}$ ) was incubated in $50 \mathrm{mM}$ phosphate buffer ( $\mathrm{pH} 7.4$ ) with $0.05 \%$ $\mathrm{DDM}$ at $37^{\circ} \mathrm{C}$. CD spectra were recorded before (blue) and after (red) incubation for $48 \mathrm{~h}$. The spectra were corrected for $50 \mathrm{mM}$ sodium phosphate ( $\mathrm{pH} 7.4$ ) with $0.05 \%$ DDM. A minimum of three scans was averaged per time point. The experiment was repeated twice; a representative data set is presented.

spectrum of LacY as obtained from the purification and before incubation possesses characteristic minima at 208 and $223 \mathrm{~nm}$, indicative of a highly $\alpha$-helical structure, in accord with the LacY native fold. ${ }^{57}$ The signal intensity was reduced significantly after incubation of the sample at $37^{\circ} \mathrm{C}$, indicating a loss of soluble protein. This result indicates that only soluble protein is being detected, while the aggregated fraction crashes out of solution and does not result in a detectable signal. Further secondary structure determination therefore was performed using FT-IR spectroscopy. This technique furthermore has a higher sensitivity and accuracy for resolving $\beta$-sheet compositions. $^{38-60}$ For example, whereas only changes in $\alpha$ helical content could be detected by CD spectroscopy in the study of the secondary structure changes of opsin variants, changes in both $\alpha$-helical and $\beta$-sheet content were observed for the same system using FT-IR spectroscopy. ${ }^{28}$ As FT-IR requires protein concentrations higher than those obtained from the purification procedure, a concentrated sample was used for this analysis. The DDM concentration of the concentrated samples was verified via colorimetric determination of the glycoside content, ${ }^{49}$ and only small increases [from 0.050 to $0.057 \%$ (Table S1)] were detected. Aliquots from the LacY solution at a concentration of $16 \mu \mathrm{M}$ were taken before and after incubation at $37{ }^{\circ} \mathrm{C}$ for $48 \mathrm{~h}$, and FT-IR spectra were recorded for each sample (Figure 5A). The amide $\mathrm{I} / \mathrm{II}$ regions of the spectra at both time points are shown, as well as the second-derivative spectra (Figure 5B).

The amide I band obtained for the LacY sample before incubation has its maximum at $1653 \mathrm{~cm}^{-1}$, which is the characteristic region for $\alpha$-helical/disordered structure content. $^{61,62}$ This preincubation sample, although predominantly $\alpha$-helical in nature, may contain some aggregated species because of its high protein concentration. After $48 \mathrm{~h}$, the main peak is shifted to $1623 \mathrm{~cm}^{-1}$, where intermolecular $\beta$-sheet structure has its characteristic maximum. ${ }^{61}$ The differences between $\beta$-sheet structure in amyloid-like fibrils compared to that in native states of proteins is evident from FT-IR data, with amyloid-like fibrils specifically populating the amide I region between 1610 and $1630 \mathrm{~cm}^{-1}$. ${ }^{63}$ A shift of the amide II band to lower wavelengths further reflects the formation of intermolecular hydrogen bonds upon incubation of the sample at $37^{\circ} \mathrm{C}$ for $48 \mathrm{~h}$. Deconvolution of the FT-IR data in Figure 5A indicates the conversion of mainly $\alpha$-helical structure to a $35 \%$ parallel $\beta$-sheet conformation after incubation at $37^{\circ} \mathrm{C}$ for $48 \mathrm{~h}$. In addition, the $\beta$-turn conformation $\left(1682 \mathrm{~cm}^{-1}\right)$ and antiparallel $\beta$-sheet $\left(1695 \mathrm{~cm}^{-1}\right)$ contents slightly increase upon incubation of the sample, and these changes are intimately related to formation of cross- $\beta$ sheet structure. ${ }^{63}$ The FT-IR data thus indicate that the nature of the $\beta$-sheet fraction is typical of amyloid-like fibrils. ${ }^{63}$

Denaturant Resistant LacY Aggregates Have a Fibrillar Architecture. In light of the fibrillar nature of the aggregated samples indicated by the ThT assay and FT-IR data, we set out to obtain the corresponding fiber diffraction patterns. The diffraction patterns of the LacY sample after incubation at $37^{\circ} \mathrm{C}$ for $48 \mathrm{~h}$ (Figure $6 \mathrm{~A}$ ) show a diffuse ring at a spacing between 4.5 and $4.8 \AA$ and a very weak reflection at $\sim 10 \AA$. While the observation of these reflections does confirm that fibrillar species are present, the weakness of the signal is a

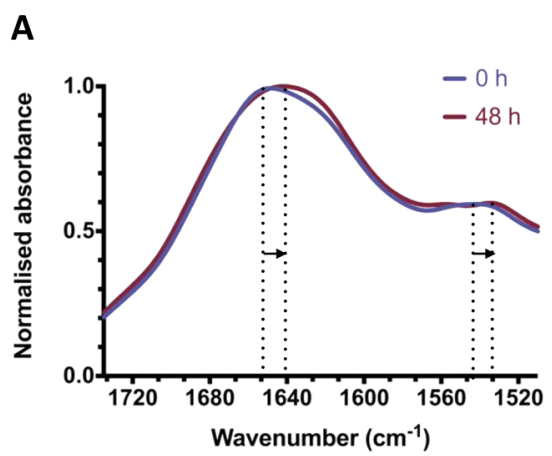

B

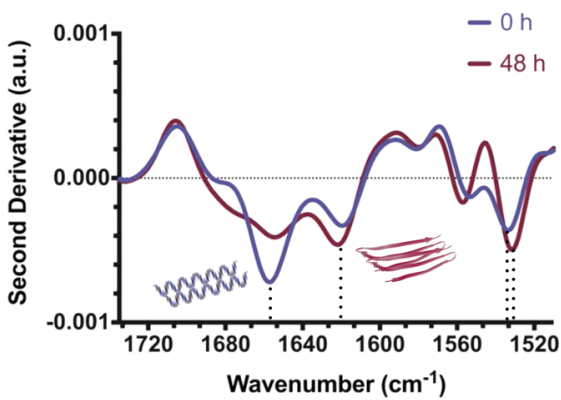

Figure 5. Secondary structure in LacY aggregates detected using FT-IR. (A) LacY (16 $\mu \mathrm{M})$ was incubated in $50 \mathrm{mM}$ phosphate buffer (pH 7.4) with $0.05-0.06 \% \mathrm{DDM}$ at $37^{\circ} \mathrm{C}$. FT-IR spectra were recorded before (blue) and after (red) incubation for $48 \mathrm{~h}$ and corrected by subtracting the spectrum of the buffer solution. The dotted lines indicate the peak maxima, and the arrows illustrate the peak shifts. A spectrum of LacY prior to concentration is not shown, because the protein directly obtained from the purification was not concentrated enough to result in a detectable spectrum. (B) Second derivative of the spectra before (blue) and after (red) incubation for $48 \mathrm{~h}$ showing the appearance of peak positions in the amide I region at 1653 and $1623 \mathrm{~cm}^{-1}$, respectively. The dotted lines indicate the main peak minima. The experiment was repeated twice; a representative data set is presented. 

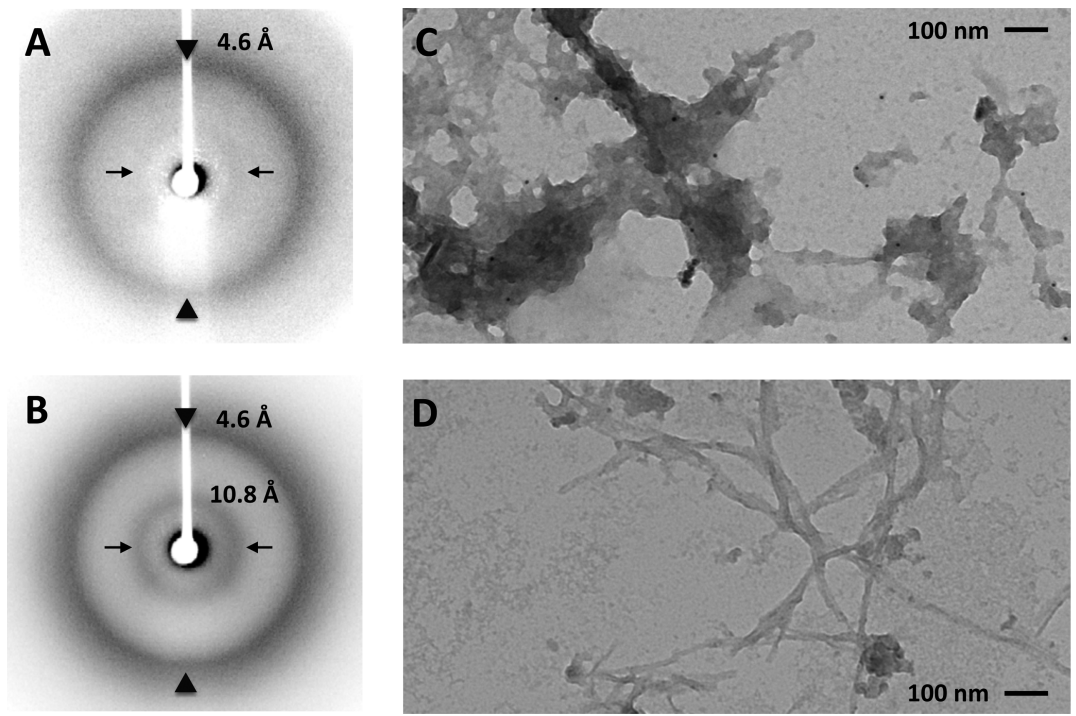

Figure 6. TEM and $\mathrm{X}$-ray fiber diffraction data of LacY aggregates. (A) LacY $(16-32 \mu \mathrm{M}$ ) was incubated in $50 \mathrm{mM}$ phosphate buffer (pH 7.4) with $0.05-0.06 \% \mathrm{DDM}$ at $37^{\circ} \mathrm{C}$. Fiber diffraction patterns from air-dried stalks of the samples were measured for the samples incubated for $48 \mathrm{~h}$ and $(\mathrm{B})$ samples treated with guanidinium hydrochloride. The arrowheads indicate the reflections at $\sim 4.6 \AA$, while the arrows indicate the reflections at $\sim 10.8$ Å. TEM grids were prepared for the same samples (C) after incubation for $48 \mathrm{~h}$ and (D) after incubation for $48 \mathrm{~h}$ followed by washing with $3 \mathrm{M}$ guanidinium hydrochloride. These experiments were repeated three times, and representative diffraction patterns and TEM images are shown.

consequence of the low concentrations of fibrils and/or of a dilution effect due to the presence of less ordered species. To gain more insights into the morphology of the species present in the LacY aggregates, transmission electron microscopy (TEM) images were recorded for the incubated $\left(37^{\circ} \mathrm{C}\right.$ for 48 h) LacY sample (concentration of 16-32 $\mu \mathrm{M}$ ). These measurements, although not sufficiently accurate to reveal quantitative parameters such as width and height, showed that the aggregates have a fibrillar morphology but are coated with less ordered material (Figure 6C), suggesting that the low resolution of the diffraction pattern is at least in part a consequence of dilution by disordered species.

To obtain more detailed images of the fibrillar species in the samples, we set out to separate the fibrillar and disordered components of the aggregates. Amyloid-like fibrils are typically extremely stable and considerably more resistant to relatively high concentrations of denaturant than disordered aggregates are. ${ }^{64}$ We therefore incubated the aggregates in urea $(8 \mathrm{M})$ or guanidinium hydrochloride $(3 \mathrm{M})$ for $1 \mathrm{~h}$, centrifuged the remaining insoluble material, and re-examined it via TEM. The samples prepared in this manner show clearly the presence of substantially more homogeneous structures (Figure 6D), indicating that a denaturant resistant fibrillar fraction can be isolated. Following treatment of the samples in urea $(8 \mathrm{M})$ or guanidinium hydrochloride $(3 \mathrm{M})$, the diffraction pattern was seen to be much more highly resolved as well (Figure 6B), showing reflections at $4.6 \AA$, characteristic of interstrand spacing, and at $10.8 \AA$, corresponding to the intersheet spacing as observed in amyloid fibrils. ${ }^{2}$ The combination of these reflections is consistent with the cross- $\beta$ pattern indicative of a $\beta$-sheet core structure, in which the constituent $\beta$-strands lie at right angles to the axis of the fibril. The characterized interstrand and intersheet spacing, in combination with an extended degree of $\beta$-sheet content, enhanced ThT fluorescence emission, and evidence of a fibrillar morphology indicates the ability of LacY to convert into amyloid-like fibrils in vitro.

\section{CONCLUSIONS}

The generality of the amyloid phenomenon has been firmly established for cytosolic proteins through a large number of case studies. ${ }^{1-8,10}$ By contrast, its extent remains rather unclear for membrane proteins, for which the conversion into $\beta$-sheetrich aggregates has been previously suggested, ${ }^{16,23,28,31,32}$ but only preliminary evidence of fibril formation so far has been provided. ${ }^{16,23,32}$ In this work, we have reported an extensive characterization of aggregates of LacY as amyloid-like fibrils. As many membrane proteins have sequences and overall architectures similar in nature to those of LacY, we anticipate that amyloid-like structures will be described in detail for a wider range of membrane proteins, and under a variety of conditions, thus allowing the biological relevance of these aggregates to be progressively defined.

\section{ASSOCIATED CONTENT}

\section{S Supporting Information}

The Supporting Information is available free of charge on the ACS Publications website at DOI: 10.1021/acs.biochem.7b00157.

DDM concentrations of LacY samples after concentration (Table S1) and ThT intensity profiles for the DDM-containing buffer in the absence of protein (Figure S1) (PDF)

\section{AUTHOR INFORMATION}

\section{Corresponding Author}

*E-mail: mv245@cam.ac.uk. Phone: +44 1223763873.

\section{ORCID}

Janet R. Kumita: 0000-0002-3887-4964

Michele Vendruscolo: 0000-0002-3616-1610

\section{Funding}

We are grateful for the award of the Marie Curie Career Development Fellowship (K.S.) and for support of this work by a Wellcome Trust Programme Grant 094425/Z/10/Z (C.M.D. 
and M.V.) and by an ERC Advanced Grant (294342) (N.J.H., P.J.B.).

\section{Notes}

The authors declare no competing financial interest.

\section{ACKNOWLEDGMENTS}

The authors thank Prof. Kathryn Lilley and Dr. Daniel Nightingale of the Cambridge Centre for Proteomics for the use of the ultracentrifuge, Dr. Ewa Klimont for the help with setting up the membrane protein purification procedures in Cambridge, Dr. Francesco Simone Ruggeri for the help with the FT-IR deconvolution, and Dr. Lyn Carter and Dr. Jeremy Skepper of the Cambridge Advanced Imaging Centre (CAIC), University of Cambridge, for the help with acquiring the TEM images. The X-ray fiber diffraction experiments were performed in the Crystallographic X-ray Facility (CXF) at the Department of Biochemistry of the University of Cambridge (DYC).

\section{REFERENCES}

(1) Sipe, J. D., and Cohen, A. S. (2000) Review: History of the amyloid fibril. J. Struct. Biol. 130, 88-98.

(2) Eisenberg, D., and Jucker, M. (2012) The amyloid state of proteins in human diseases. Cell 148, 1188-1203.

(3) Knowles, T. P. J., Vendruscolo, M., and Dobson, C. M. (2014) The amyloid state and its association with protein misfolding diseases. Nat. Rev. Mol. Cell Biol. 15, 384-396.

(4) Chiti, F., and Dobson, C. M. (2006) Protein misfolding, functional amyloid, and human disease. Annu. Rev. Biochem. 75, 333366.

(5) Sunde, M., Serpell, L. C., Bartlam, M., Fraser, P. E., Pepys, M. B., and Blake, C. C. F. (1997) Common core structure of amyloid fibrils by synchrotron X-ray diffraction. J. Mol. Biol. 273, 729-739.

(6) Glenner, G. G., Eanes, E. D., Bladen, H. A., Linke, R. P., and Termine, J. D. (1974) Beta-pleated sheet fibrils - comparison of native amyloid with synthetic protein fibrils. J. Histochem. Cytochem. 22, $1141-1158$.

(7) Chiti, F., Webster, P., Taddei, N., Clark, A., Stefani, M., Ramponi, G., and Dobson, C. M. (1999) Designing conditions for in vitro formation of amyloid protofilaments and fibrils. Proc. Natl. Acad. Sci. U. S. A. 96, 3590-3594.

(8) Fandrich, M., Fletcher, M. A., and Dobson, C. M. (2001) Amyloid fibrils from muscle myoglobin - Even an ordinary globular protein can assume a rogue guise if conditions are right. Nature 410, $165-166$.

(9) Guijarro, J. I., Sunde, M., Jones, J. A., Campbell, I. D., and Dobson, C. M. (1998) Amyloid fibril formation by an SH3 domain. Proc. Natl. Acad. Sci. U. S. A. 95, 4224-4228.

(10) Dobson, C. M. (1999) Protein misfolding, evolution and disease. Trends Biochem. Sci. 24, 329-332.

(11) Rath, A., and Deber, C. M. (2007) Membrane protein assembly patterns reflect selection for non-proliferative structures. FEBS Lett. 581, 1335-1341.

(12) Walther, D. M., Kasturi, P., Zheng, M., Pinkert, S., Vecchi, G., Ciryam, P., Morimoto, R. I., Dobson, C. M., Vendruscolo, M., Mann, M., and Hartl, F. U. (2015) Widespread proteome remodeling and aggregation in aging C-elegans. Cell 161, 919-932.

(13) Ciryam, P., Kundra, R., Freer, R., Morimoto, R. I., Dobson, C. M., and Vendruscolo, M. (2016) A transcriptional signature of Alzheimer's disease is associated with a metastable subproteome at risk for aggregation. Proc. Natl. Acad. Sci. U. S. A. 113, 4753-4758.

(14) Ciryam, P., Tartaglia, G. G., Morimoto, R. I., Dobson, C. M., and Vendruscolo, M. (2013) Widespread aggregation and neurodegenerative diseases are associated with supersaturated proteins. Cell Rep. 5, 781-790.

(15) Kang, J., Lemaire, H. G., Unterbeck, A., Salbaum, J. M., Masters, C. L., Grzeschik, K. H., Multhaup, G., Beyreuther, K., and Mullerhill,
B. (1987) The precursor of Alzheimers disease amyloid-a4 protein resembles a cell-surface receptor. Nature 325, 733-736.

(16) Berson, J. F., Theos, A. C., Harper, D. C., Tenza, D., Raposo, G., and Marks, M. S. (2003) Proprotein convertase cleavage liberates a fibrillogenic fragment of a resident glycoprotein to initiate melanosome biogenesis. J. Cell Biol. 161, 521-533.

(17) Wagner, S., Baars, L., Ytterberg, A. J., Klussmeier, A., Wagner, C. S., Nord, O., Nygren, P.-A., van Wijk, K. J., and de Gier, J.-W. (2007) Consequences of membrane protein overexpression in Escherichia coli. Mol. Cell. Proteomics 6, 1527-1550.

(18) Harris, N. J., and Booth, P. J. (2012) Folding and stability of membrane transport proteins in vitro. Biochim. Biophys. Acta, Biomembr. 1818, 1055-1066.

(19) Krogh, A., Larsson, B., von Heijne, G., and Sonnhammer, E. L. L. (2001) Predicting transmembrane protein topology with a hidden Markov model: Application to complete genomes. J. Mol. Biol. 305, $567-580$.

(20) Overington, J. P., Al-Lazikani, B., and Hopkins, A. L. (2006) Opinion - How many drug targets are there? Nat. Rev. Drug Discovery 5, 993-996.

(21) Welsh, M. J., and Smith, A. E. (1993) Molecular mechanisms of CFTR chloride channel dysfunction in cystic fibrosis. Cell 73, 12511254.

(22) Ward, C. L., Omura, S., and Kopito, R. R. (1995) Degradation of CFTR by the ubiquitin-proteasome pathway. Cell 83, 121-127.

(23) Wigley, W. C., Corboy, M. J., Cutler, T. D., Thibodeau, P. H., Oldan, J., Lee, M. G., Rizo, J., Hunt, J. F., and Thomas, P. J. (2002) A protein sequence that can encode native structure by disfavoring alternate conformations. Nat. Struct. Biol. 9, 381-388.

(24) Hartong, D. T., Berson, E. L., and Dryja, T. P. (2006) Retinitis pigmentosa. Lancet 368, 1795-1809.

(25) Krebs, M. P., Holden, D. C., Joshi, P., Clark, C. L., III, Lee, A. H., and Kaushal, S. (2010) Molecular mechanisms of rhodopsin retinitis pigmentosa and the efficacy of pharmacological rescue. J. Mol. Biol. 395, 1063-1078.

(26) Saliba, R. S., Munro, P. M. G., Luthert, P. J., and Cheetham, M. E. (2002) The cellular fate of mutant rhodopsin: quality control, degradation and aggresome formation. J. Cell Sci. 115, 2907-2918.

(27) Surguchev, A., and Surguchov, A. (2010) Conformational diseases: Looking into the eyes. Brain Res. Bull. 81, 12-24.

(28) Miller, L. M., Gragg, M., Kim, T. G., and Park, P. S. H. (2015) Misfolded opsin mutants display elevated beta-sheet structure. FEBS Lett. 589, 3119-3125.

(29) Yamada, K., Sato, J., Oku, H., and Katakai, R. (2003) Conformation of the transmembrane domains in peripheral myelin protein 22. Part 1. Solution-phase synthesis and circular dichroism study of protected 17-residue partial peptides in the first putative transmembrane domain. J. Pept. Res. 62, 78-87.

(30) Naef, R., and Suter, U. (1998) Many facets of the peripheral myelin protein PMP22 in myelination and disease. Microsc. Res. Tech. 41, 359-371.

(31) Ryan, M. C., Shooter, E. M., and Notterpek, L. (2002) Aggresome formation in neuropathy models based on peripheral myelin protein 22 mutations. Neurobiol. Dis. 10, 109-118.

(32) Danoff, E. J., and Fleming, K. G. (2015) Aqueous, unfolded OmpA forms amyloid-like fibrils upon self-association. PLoS One 10, e0132301.

(33) Abramson, J., Smirnova, I., Kasho, V., Verner, G., Kaback, H. R, and Iwata, S. (2003) Structure and mechanism of the lactose permease of Escherichia coli. Science 301, 610-615.

(34) Guan, L., Mirza, O., Verner, G., Iwata, S., and Kaback, H. R. (2007) Structural determination of wild-type lactose permease. Proc. Natl. Acad. Sci. U. S. A. 104, 15294-15298.

(35) Guan, L., and Kaback, H. R. (2006) Lessons from lactose permease. Annu. Rev. Biophys. Biomol. Struct. 35, 67-91.

(36) Madej, M. G. (2014) Function, structure, and evolution of the Major Facilitator Superfamily: the LacY manifesto. Adv. Biol. 2014, 120. 
(37) Harris, N. J., Findlay, H. E., Simms, J., Liu, X., and Booth, P. J. (2014) Relative domain folding and stability of a membrane transport protein. J. Mol. Biol. 426, 1812-1825.

(38) Findlay, H. E., and Booth, P. J. (2013) Folding alpha-helical membrane proteins into liposomes in vitro and determination of secondary structure. Methods Mol. Biol. 1063, 117-124.

(39) Sanders, C. R, and Mittendorf, K. F. (2011) Tolerance to changes in membrane lipid composition as a selected trait of membrane proteins. Biochemistry 50, 7858-7867.

(40) Alder, N. N., and Johnson, A. E. (2004) Cotranslational membrane protein biogenesis at the endoplasmic reticulum. J. Biol. Chem. 279, 22787-22790.

(41) Vembar, S. S., and Brodsky, J. L. (2008) One step at a time: endoplasmic reticulum-associated degradation. Nat. Rev. Mol. Cell Biol. 9, 944-957.

(42) Ibstedt, S., Sideri, T. C., Grant, C. M., and Tamas, M. J. (2014) Global analysis of protein aggregation in yeast during physiological conditions and arsenite stress. Biol. Open 3, 913-923.

(43) Liao, L., Cheng, D., Wang, J., Duong, D. M., Losik, T. G., Gearing, M., Rees, H. D., Lah, J. J., Levey, A. I., and Peng, J. (2004) Proteomic characterization of postmortem amyloid plaques isolated by laser capture microdissection. J. Biol. Chem. 279, 37061-37068.

(44) Sergeant, N., Wattez, A., Galvan-Valencia, M., Ghestem, A., David, J. P., Lemoine, J., Sautiere, P.-E., Dachary, J., Mazat, J. P., Michalski, J. C., Velours, J., Mena-Lopez, R., and Delacourte, A. (2003) Association of ATP synthase alpha-chain with neurofibrillary degeneration in Alzheimer's disease. Neuroscience 117, 293-303.

(45) Murakami, T., Shoji, M., Imai, Y., Inoue, H., Kawarabayashi, T., Matsubara, E., Harigaya, Y., Sasaki, A., Takahashi, R., and Abe, K. (2004) Pael-R is accumulated in Lewy bodies of Parkinson's disease. Ann. Neurol. 55, 439-442.

(46) Sormanni, P., Aprile, F. A., and Vendruscolo, M. (2015) The CamSol method of rational design of protein mutants with enhanced solubility. J. Mol. Biol. 427, 478-490.

(47) Guan, L., Murphy, F. D., and Kaback, H. R. (2002) Surfaceexposed positions in the transmembrane helices of the lactose permease of Escherichia coli determined by intermolecular thiol cross-linking. Proc. Natl. Acad. Sci. U. S. A. 99, 3475-3480.

(48) Strop, P., and Brunger, A. T. (2005) Refractive index-based determination of detergent concentration and its application to the study of membrane proteins. Protein Sci. 14, 2207-2211.

(49) Urbani, A., and Warne, T. (2005) A colorimetric determination for glycosidic and bile salt-based detergents: applications in membrane protein research. Anal. Biochem. 336, 117-124.

(50) Kelly, S. M., Jess, T. J., and Price, N. C. (2005) How to study proteins by circular dichroism. Biochim. Biophys. Acta, Proteins Proteomics 1751, 119-139.

(51) Kuhlbrandt, W. (1988) 3-Dimensional cystallization of membrane-proteins. Q. Rev. Biophys. 21, 429-477.

(52) Engel, C. K., Chen, L., and Privé, G. G. (2002) Stability of the lactose permease in detergent solutions. Biochim. Biophys. Acta, Biomembr. 1564, 47-56.

(53) Biancalana, M., and Koide, S. (2010) Molecular mechanism of Thioflavin-T binding to amyloid fibrils. Biochim. Biophys. Acta, Proteins Proteomics 1804, 1405-1412.

(54) Khurana, R., Coleman, C., Ionescu-Zanetti, C., Carter, S. A., Krishna, V., Grover, R. K., Roy, R., and Singh, S. (2005) Mechanism of thioflavin T binding to amyloid fibrils. J. Struct. Biol. 151, 229-238.

(55) Kumar, S., Singh, A. K., Krishnamoorthy, G., and Swaminathan, R. (2008) Thioflavin $T$ displays enhanced fluorescence selectively inside anionic micelles and mammalian cells. J. Fluoresc. 18, 11991205.

(56) Bouchard, M., Zurdo, J., Nettleton, E. J., Dobson, C. M., and Robinson, C. V. (2000) Formation of insulin amyloid fibrils followed by FTIR simultaneously with CD and electron microscopy. Protein Sci. 9, 1960-1967.

(57) Foster, D. L., Boublik, M., and Kaback, H. R. (1983) Structure of the lac carrier protein of Escherichia-coli. J. Biol. Chem. 258, 31-34.
(58) Uversky, V. N., Li, J., and Fink, A. L. (2001) Evidence for a partially folded intermediate in alpha-synuclein fibril formation. J. Biol. Chem. 276, 10737-10744.

(59) Barth, A., and Zscherp, C. (2002) What vibrations tell us about proteins. Q. Rev. Biophys. 35, 369-430.

(60) Calero, M., and Gasset, M. (2012) Featuring amyloids with fourier transform infrared and circular dichroism spectroscopies. Methods Mol. Biol. 849, 53-68.

(61) Krimm, S., and Bandekar, J. (1986) Vibrational spectroscopy and conformation of peptides, polypeptides, and proteins. Adv. Protein Chem. 38, 181-364.

(62) Arrondo, J. L. R., Muga, A., Castresana, J., and Goni, F. M. (1993) Quantitative studies of the structure of proteins in solution by fourier-transform infrared-spectroscopy. Prog. Biophys. Mol. Biol. 59, $23-56$.

(63) Zandomeneghi, G., Krebs, M. R. H., McCammon, M. G., and Fandrich, M. (2004) FTIR reveals structural differences between native beta-sheet proteins and amyloid fibrils. Protein Sci. 13, 33143321.

(64) Baldwin, A. J., Knowles, T. P. J., Tartaglia, G. G., Fitzpatrick, A. W., Devlin, G. L., Shammas, S. L., Waudby, C. A., Mossuto, M. F., Meehan, S., Gras, S. L., Christodoulou, J., Anthony-Cahill, S. J., Barker, P. D., Vendruscolo, M., and Dobson, C. M. (2011) Metastability of native proteins and the phenomenon of amyloid formation. J. Am. Chem. Soc. 133, 14160-14163. 